\title{
June 2020
}
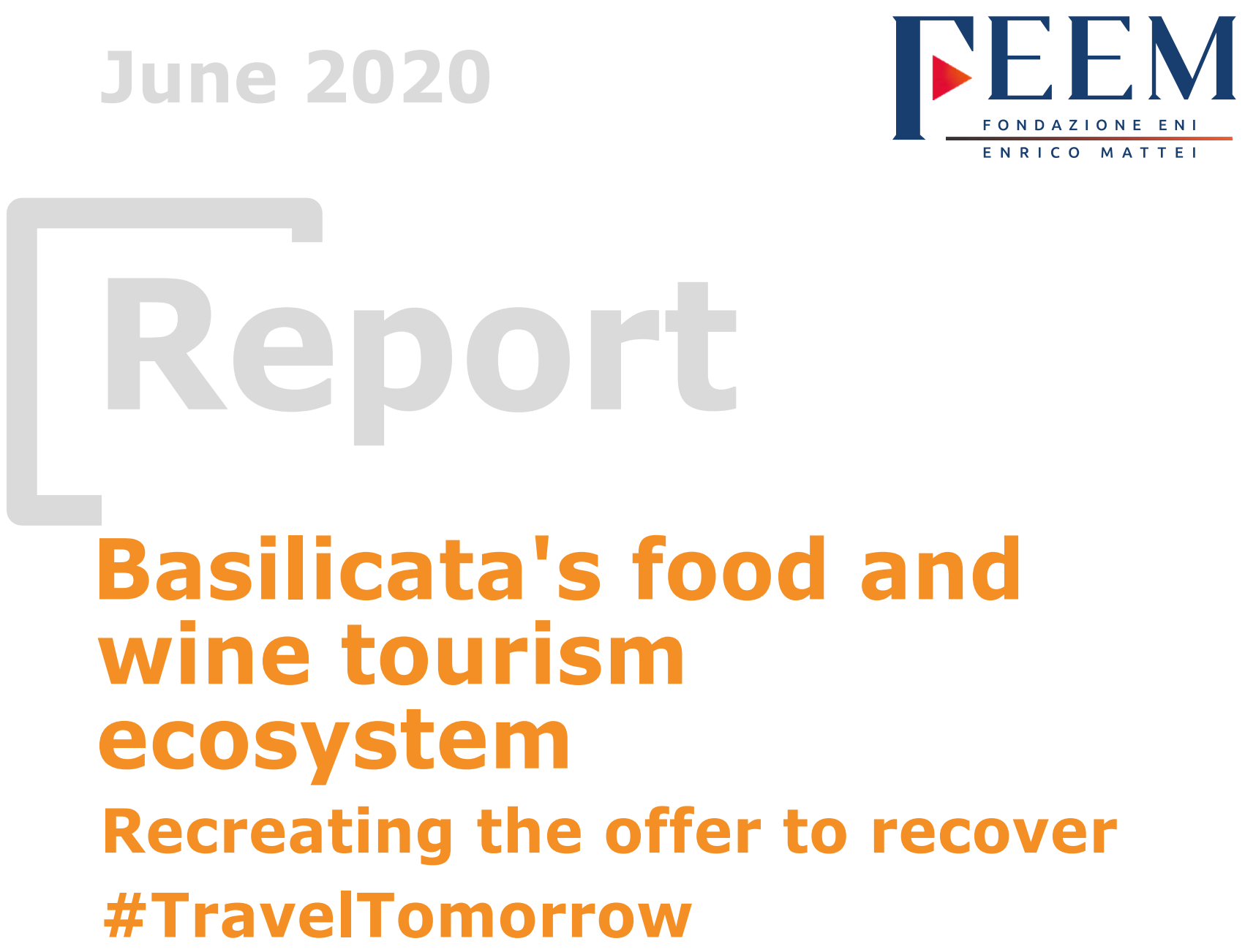

Angelo Bencivenga, Annalisa Percoco

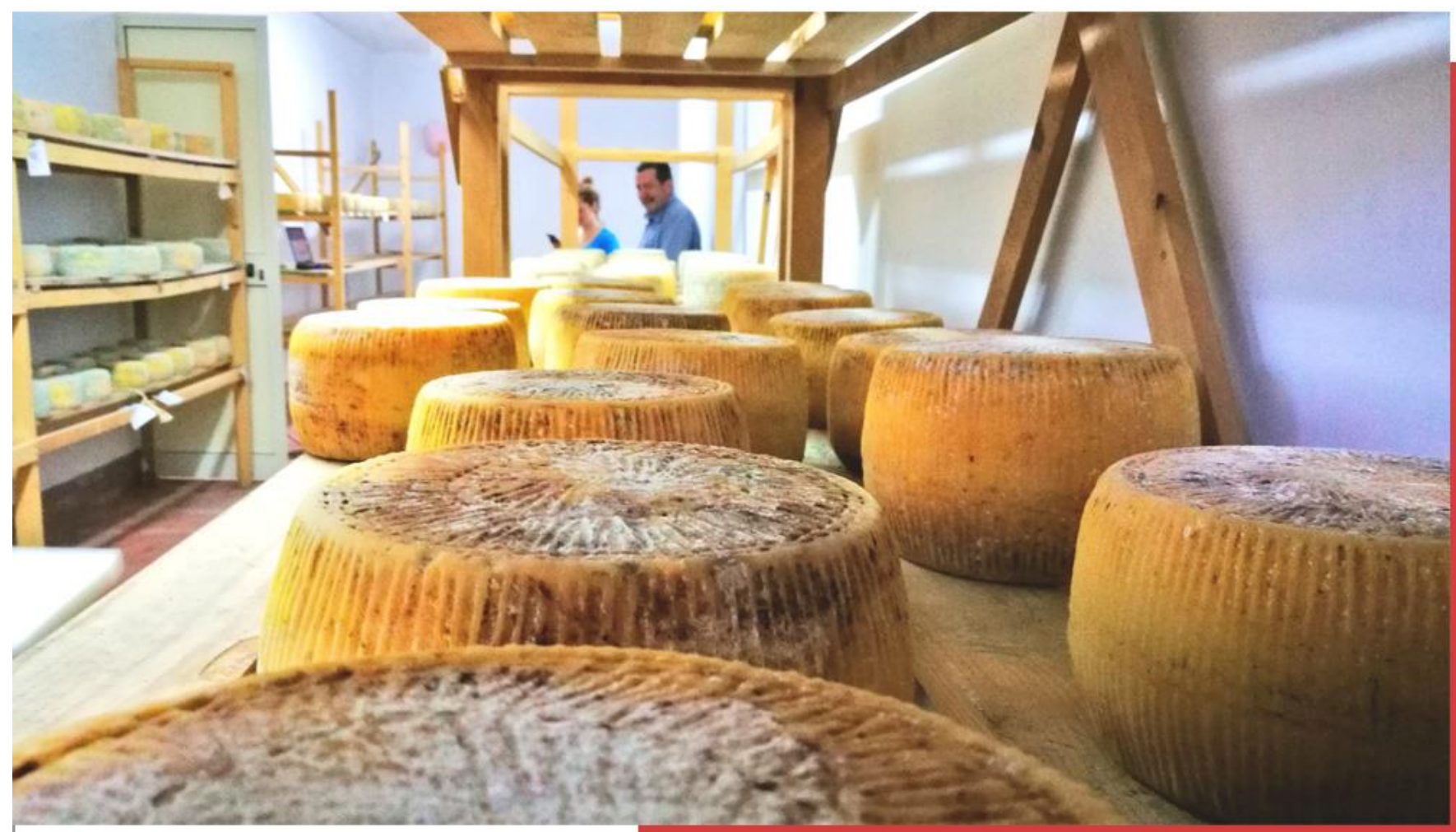


Basilicata's food and wine tourism ecosystem Recreating the offer to recover \#TravelTomorrow

\section{FEEM}




\section{Excutive Summary}

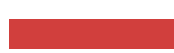

The growing competition between tourist destinations drives territories to continuous innovation with the aim of positioning themselves in an increasingly crowded market, and the search for positioning involves creation of new tourism products based on the authenticity, sustainability and originality of the destination especially after shock situations such as Covid 19.

The travel ban seems to be the right moment to speed up reorganisation of a territorial offer able to satisfy the demand for sustainability to which the need for security has been added. A tourism product able to meet these needs is food and wine tourism.

The challenge for destinations is therefore to make use of the obvious advantages of food and wine tourism through technological innovation but above al through a process innovation based on knowledge and organisation of their territory in order to build a tourism offer designed according to the market logic.

Starting from the concept of a tourism product and the importance that food and wine tourism could have for a rural region like Basilicata situated in the south of Italy, we have envisaged the food and wine tourism ecosystem as a model able to

determine local development through the involvement of all the players essential to the holistic development of the territory. 


\section{Index}

Executive Summary

Introduction

Food and wine tourism and sustainable tourism goals

Food and wine tourism in offers by the tourist destinations

Creating tourism products

Basilicata's food and wine tourism ecosystem

Conclusions

Bibliography 
STAY HOME TODAY,

\#TRAVELTOMORROW. The hashtag

launched during the Covid 19 pandemic by the World Tourism Organization

expresses the dramatic situation and at the same time hope for the tourism industry, which is an expression of

economic development but above all of personal growth and knowledge of different cultures.

Due to the spread of the coronavirus, whole economic systems will come to a sudden halt, and there is talk of a $1 / 2$ point reduction in global GDP (OECD).

One of the worst affected sectors is tourism, and the World Tourism Organization has estimated 20-30\%

fewer international arrivals compared to 2019 with losses amounting to 300 450 billion dollars for the entire secto (estimates made on March 27, 2020).

In Europe, the tourism industry is the third largest sector of the European economy, generating $10.3 \%$ of GDP and providing jobs for 27 million people.

It is clear that the current situation is in danger of wiping out millions of jobs within the sector as well as destroying its productive fabric, $80 \%$ of which is made up of small and medium-sized tourism enterprises (SMEs) that create opportunities for women, young people and rural communities, and it is precisely these internal areas that risk having their economies wiped out when they could sustain and develop sustainably thanks to tourism.
Yet we believe that precisely this symmetrical crisis could become an opportunity for rural areas to establis themselves as new tourist destinations capable of responding to future demand, but for this to happen, the appeal of these smaller destinations must be redefined and in many cases created.

To this end, today more than ever before, we believe that food and wine tourism can represent a tourism product that is able to support these locations and ensure their sustainable development.

Food and wine tourism represents a unique resource for tourist destinations that want to position themselves in an increasingly competitive market and that intend to base their development on sustainability.

There are various reasons behind this statement, the first being that there is a growing demand for this kind of tourism, which is able to express the culture traditions, authenticity and

sustainability of a location. The second derives from the need for tourist destinations to differentiate themselves from their competition and consequently the need to create unique and authentic tourism products, and in this sense food and wine tourism becomes an added value. The third is linked to the characteristics of food and wine tourism, a market segment with a higher spending power than other segments, and which is distributed more uniformly 
in space and time, thus avoiding the overcrowding of places and favouring a longer tourist season.

Finally, food and wine tourism succeeds in creating sustainable local

development thanks to its transversal nature, able to involve various

economic sectors (agriculture, crafts, services) and promote preservation of local traditions and protection of biodiversity.

This research project aims to define the strategic planning of food and wine tourism in Basilicata, a rural region of southern Italy, contributing to the growth of the local economy in a sustainable way. This aim can be achieved by creating a food and wine tourism ecosystem for Basilicata (as the initial phase of a wider strategic plan) which will be a step towards creating a food and wine tourism product sufficiently competitive and sustainable to satisfy the current demands of the tourism market.

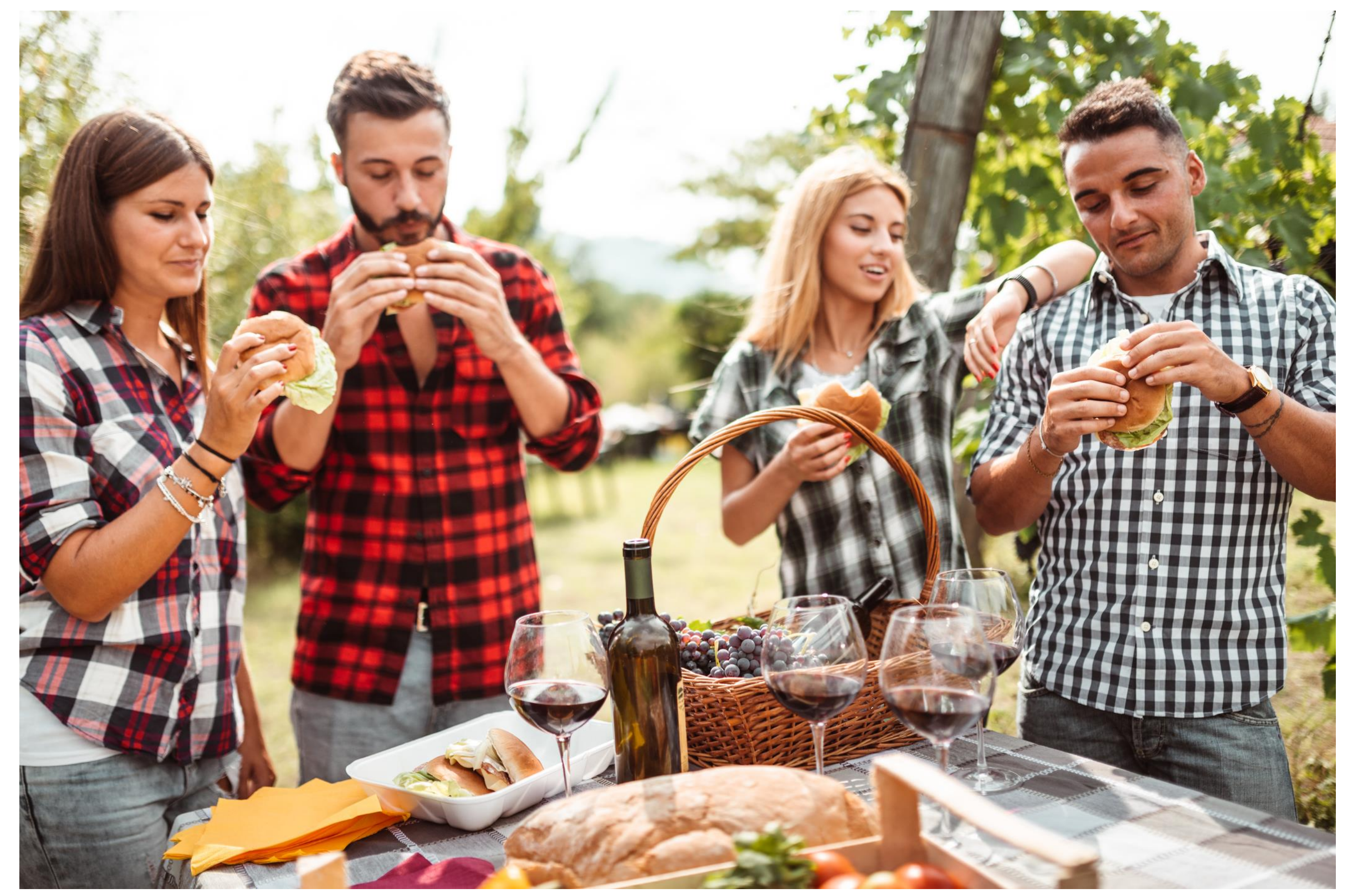


The concept of sustainability is becoming increasingly more important for tourist destinations' competitiveness, which lies in their ability to attract tourists by providing them with quality experiences while at the same time ensuring the well-being of residents; destinations enjoy a competitive advantage when they make effective use of their resources in the long term while preserving their natural capital in the future. In the past, the competitiveness of a destination was assessed exclusively in economic terms, but today the ability to compete also lies in other important aspects, and we have moved from a purely economic assessment to one in which

environmental, social and cultural aspects also play a significant role, and are increasingly important factors in the choice of a holiday destination.

For sustainability, Agenda 2030 for sustainable development is an ambitious action programme for people, the planet and prosperity signed in 2015 by the governments of the $193 \mathrm{UN}$ member countries. The Agenda includes 17 sustainable development goals which are completed by a major action programme of 169 targets. The signatory countries are committed to achieving these sustainability targets by 2030

The Agenda 2030 Goals are shared commitments on a series of important development issues: fighting poverty and hunger, promoting health and well-being, quality education, gender equality, clean water and sanitation, clean and accessible energy, decent work and economic growth, business innovation and infrastructures, reducing inequalities, fostering sustainable cities and communities, responsible consumption and production, combating climate change, protecting life under water, life on land, ensuring peace and social justice, ensuring the partnership to achieve the goals.

The United Nations Agenda 2030 for Sustainable Development identifies sustainable tourism as one of the sectors for achieving the sustainability goals, in particular target 8.9 suggests that Member States "devise and implement policies to promote sustainable tourism that creates jobs and promotes local culture and products".

Food and wine therefore falls into the areas of tourism able to promote the sustainable competitiveness of a destination, a tourism capable of involving the various levels of sustainability, distinguished by an enormous capacity to stimulate economies, especially local economies, and to promote sustainability and inclusion. Food and wine tourism is, therefore, a way to promote cultures through food, and favours sustainable tourism through the preservation of cultural heritage, bringing out local communities' pride in their identity. By taking part in gastronomy eventsery, cook classes and company visits, tourists come into close contact with the values of local culture and traditions.

The challenge for destinations is to exploit the advantages of food and wine tourism through innovation linked to technology to adapt their offerings to the needs of new tourists. In the 4th World Forum on Gastronomy Tourism held in June 2018, the World Tourism Organization highlighted the contribution that technology can make to tourism in general and food and wine tourism in particular, stating that technology should be used as a tool to preserve and promote the authenticity of local economies, thus ensuring the positive experience of tourists. UNWTO stresses the need for policies for small and medium-sized enterprises that foster innovation and digital transformation, as well as the need, through technology, to link the different players in the food and wine tourism value chain, and underlines the need to increase the involvement of tourists by harnessing social media and other tools for digital description of the territory. It concludes by saying that these are changes that require new professional skills for which specific education and training courses are crucial.

However, innovation is not synonymous with technology, innovation also means using new approaches and methods to rethink the offerings of each destination, and create tourism products able to satisfy demand. The variety and significance of tourism products provide the motivation that drives tourists to visit a destination, and creation of tourism products is part of a wider process which includes researching of tourism resources and marketing, while the tourism product is the link between supply and demand.

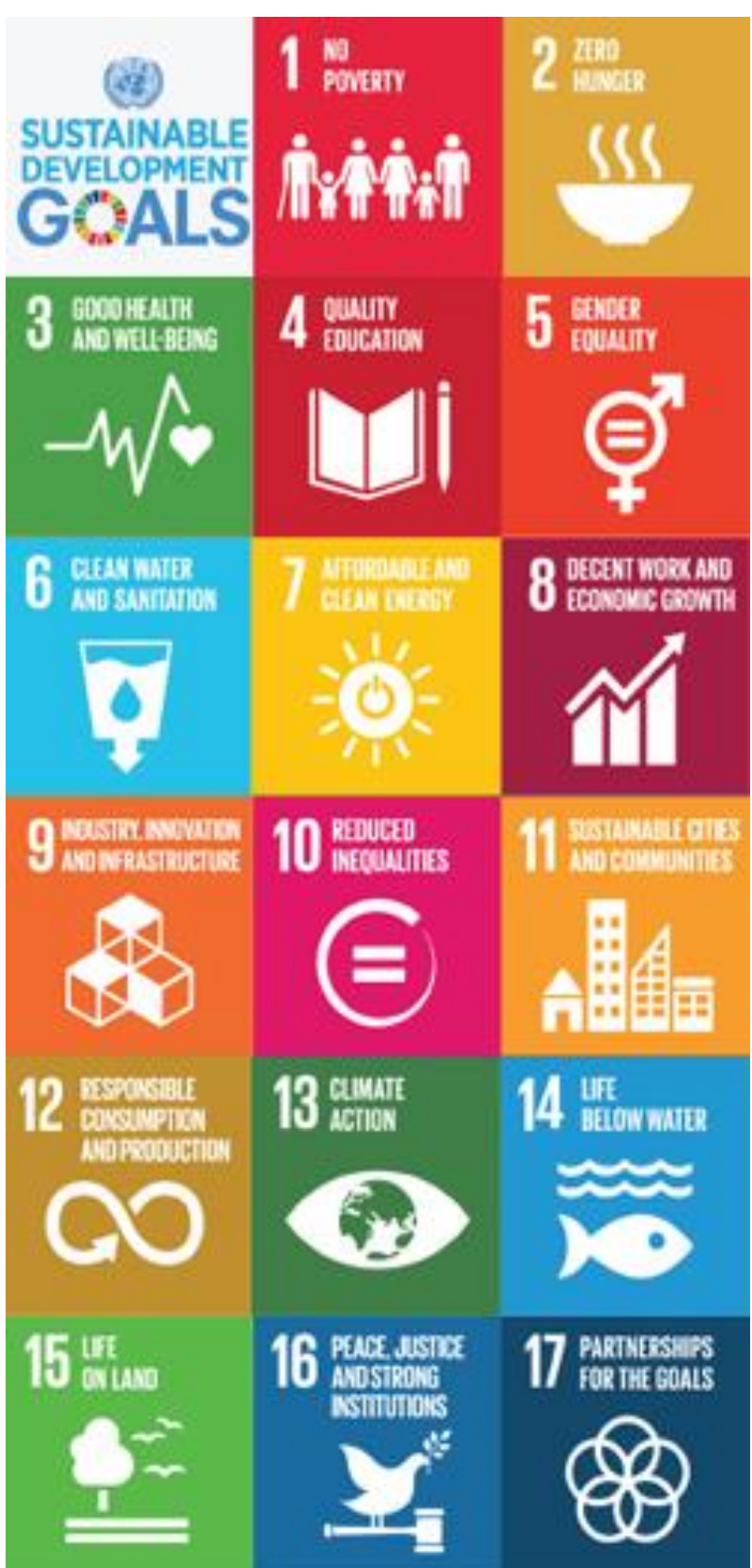

FEEM REPORTS । 11 
Food and wine tourism in offers by the tourist destinations

Food and wine are part of what are considered the new trends in the tourism market, an increasingly important trend for a destination.

On the supply side there are local systems that have based their attractiveness on traditional local products and the quality of their catering services and others, on the contrary, where the food and wine offered, even though it has increased in recent years, always plays a secondary role compared to other reasons for travel. The food and wine offer is made up of products, processes of supply, serving and sale, structures and people, and is essentially a system of supply chains; the local food and wine system, in addition to local products and gastronomic traditions, also includes restaurant facilities, the accommodation system, the sales network, reception and information facilities, festivals and dedicated events. All these aspects are based on one of the factors that drives demand and is able to have a significant effect on the perception of the location and the quality of the tourism offer, i.e. the landscape; the quality of the food and wine offered is inextricably linked to the quality of the local landscape and can only be assessed in relation to it. Each of these

components contributes to determining the attractiveness of the food and wine offered and influences, by virtue of its own quality levels, the holistic quality of the local territory, which in turn influences both the image of the location as a tourist destination and the

experience of the tourists themselves. The growing importance of food and wine tourism in the context of local development policies is a phenomenon that cannot be explained by referring exclusively to the expansive dynamics of this segment of demand or the effects on the economy and employment that it is able to determine. What characterizes food and wine tourism is its territorial significance, its ability to express and epitomize the essence of the locations. From the point of view of demand, food and wine tourism emerges as an "experience of somewhere else" by an enjoyment of the territory that privileges its intangible heritage and seeks real contact with the locations by sharing local culture in its tangible and intangible expressions.

On a local scale, food and wine tourism can promote interaction between various sectors and production chains,

determining follow-through effects on the local economy, but its importance is deeply linked to the ability to exploit the endogenous potential by making the most of local specificities and active involvement of the local community. For such effects on the territory to be generated, the food and wine offer must meet certain basic conditions. First of all, it must reflect the productive and cultural traditions of the local context in which it has developed; then, it must adapt to the needs and expectations of the tourism market; finally, it must provide for the active participation of the local community both as the repository of the knowledge on which the food and wine offer is based and from which it derives, and because this is the only way to trigger a process of endogenous development and to protect and strengthen local identity.
The critical success factor thus becomes quality, meaning both the correspondence of the food and wine offered to market expectations, and the authenticity of the offer, in its various systemic components (local products, production and culinary traditions, accommodation and catering facilities, etc.).

Therefore, the most important

contribution that food and wine tourism can offer to local development is recovery and enhancement of the specific identity of the territory. This form of tourism, in fact, by focusing on the enhancement of endogenous potential in its material and immaterial components, determines a strengthening of the sense of belonging of the local community and gives it a leading role in local development processes. It is the local identity itself that forms the basis of the attractiveness of the tourism offer.

In this sense, when speaking of food and wine tourism, it is difficult to differentiate between its enjoyment in the areas of taste, nature and culture. For this reason, the quality of the products contributes to the formation of a

territorial quality from which all types of tourism can benefit, acting as a unifying element of the local tourism offer.

Food and wine tourism can be classed as one of the new trends in the tourism market, placing it amongst the new forms of tourism.

Food and wine tourism in recent years has established itself as a growing form of

cultural tourism. By visiting producers,

eating a meal in a restaurant, taking part in cookery classes or a food and wine tour tourists rediscover the link between food and wine products and the territories where they originate.

The interests and needs of tourists falling within the segment called food and wine tourism are very varied, considering the demand in a unified way represents a shortsighted and inadequate vision for

understanding the many differences that exist.

To this end an interesting classification of food and wine tourists is provided by Hall and Sharples who, within the food and wine segment, identify clusters of tourists with different characteristics and motivations, a very useful classification for designing vertical tourism offers able to provide various experiences. 


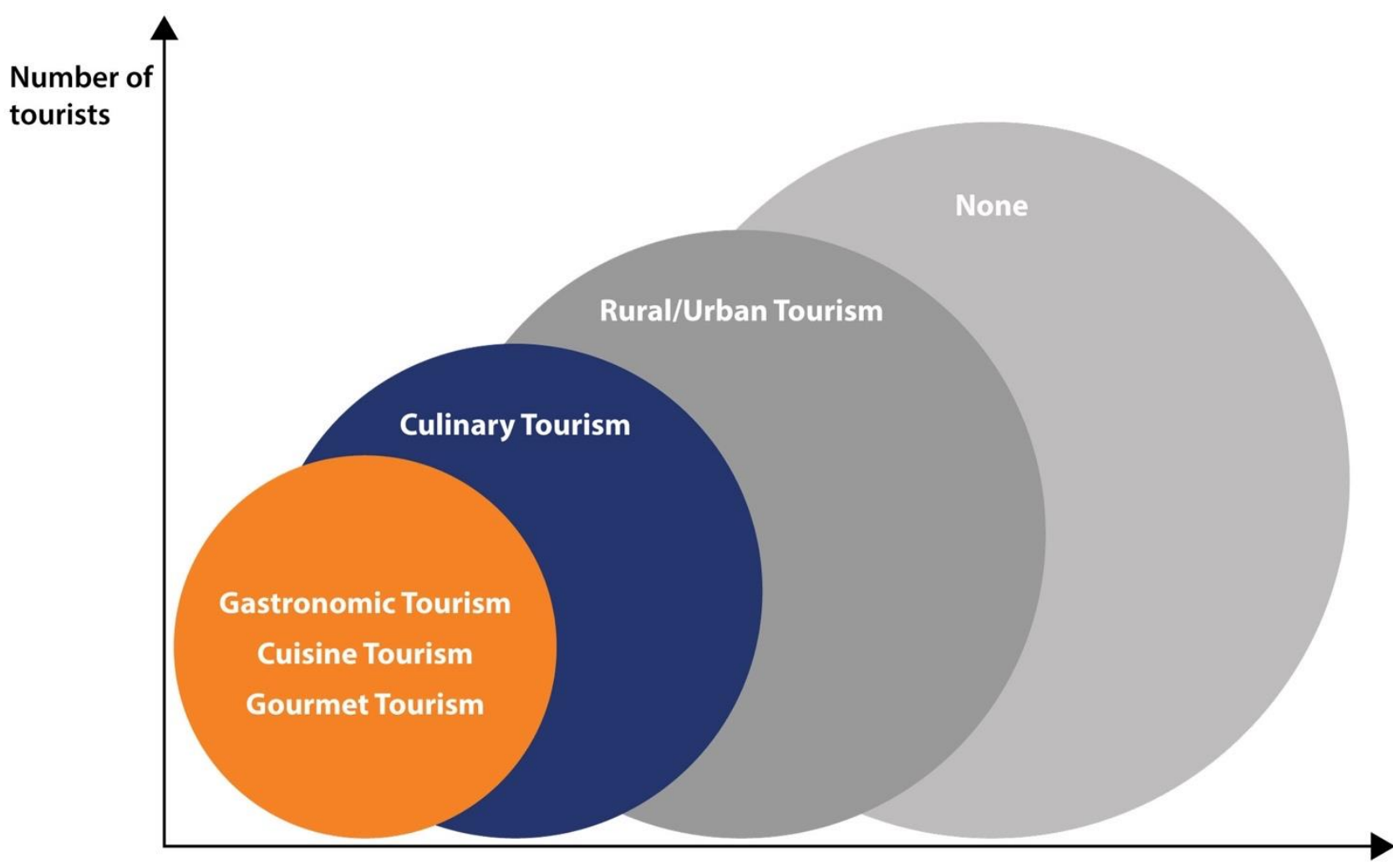

Figure 1: Level of interest in food

The authors divide food and wine tourists according to whether they are more or less strongly interested in food and wine as a motivation for travel:

High interest: Tourists for whom food is the primary motivation for travel, this segment includes gourmet tourists, gastronomic tourists and cuisine tourists.

- Moderate interest: Tourists who consider food-related activities useful for understanding the loca

- Low interest: Tourists who see food-related activities as an opportunity to gain new experiences. This segment includes urban/rural tourists.

- No interest: Tourists who consider drinking and eating simply as a way to satisfy their basic needs dictated by hunger and thirst.

The authors consider food and wine tourists to be only those who fall into the first three categories

\section{Creating tourism products}

Tourism products provide the motivation that drives tourists to visit a destination, and the tourism product forms the link between the destination and the market or between supply and demand. We could define a tourism product as a process by which a destination's wide range of resources and services are combined to create a unique experience for tourists.

The quality of each single service or resource is influenced by the quality of resource is of each sing ser service atl the others and the weakness of one atone will influence the quality of the whole supply chain, it therefore follows that there is a need to encourage cooperation and coordination of the different players in order to achieve a holistic quality standard of the entire tourism product, and the challenge for a destination is therefore to combine and integrate services and resources so as to create the right tourism product for the market demand. The purpose of a tourism product is to build the positioning of the destination based on authenticity, innovation and sustainability.

As mentioned previously, resources are fundamentat elements of the tourism product that encourage visitors ors to visit a

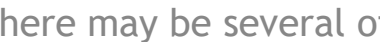
them with different characteristics. There are those on which the destination management can take little action, since they are peculiarities representing the core around which the other resources must be imagined: flora, fauna, landscape, climate, water resources. Then there are other resources on which the destination management can take extensive action: sports, cultural events, recreational and leisure activities. cultural resources, that is to say the intangible capital that provides a strong motivation for the tourist demand, are very important in terms of attractiveness, since it gives strong psychological rather than physical satisfaction.

The steps for creating the tourism product can be summarized as follows:

1) Market research to find out the demand trends, identify demand segments and their characteristics:

2) Identify tourism products that are in line with demand needs;

3) Identify the areas in which to implement the identified tourism products;

4) Identify exceptional characteristics able to provide strong motivation for tourists to

5) Based on the main areas and features, create tourist itineraries, events, festivals, etc.;

6) Start consulting all stakeholders, especially local communities, with a view to cooperation;

7) Draft a development plan for investors to present opportunities related to tourism products;

8) Imagine training programmes for the players who at various levels are called upon to implement tourism products;

9) Draw up a marketing strategy able to promote and communicate the development of tourism products with a development of tourism products with a view to a destination branding strategy. central phase of this work, and talk about Basiticata's food and wine tourism ecosystem as a fundamental and preparatory part for creating Basilicata's food and wine product, useful to position Basilicata as a sustainable destination linked to gastronomic motivation. 
Starting from the concept of a tourism product and the importance of food and wine tourism for the destination, we have imagined a conceptual model called

'Basilicata's food and wine tourism ecosystem" that identifies the various players in the chain and their role within the ecosystem. We imagined 4 levels that make up the entire ecosystem, namely: planning and management, food and wine tourism value chain, food and wine tourism product design, support for creation of the ecosystem.

The planning and management level involves identifying the public and private bodies assigned to plan and manage the

entire ecosystem; this level is positioned at the highest point of the ecosystem.
The food and wine tourism value chain level includes all the players essential to creation of the tourism product, whose variety and number depend on the numerous combinations for creation of the tourism product, players ranging from agricultural producers, catering services, accommodation services, services related to the promotion and marketing of the tourism product. The Tourism Product Design level includes food and wine tourism products that will take shape from the combination of the individual elements of the food and wine tourism value chain. Finally, the level regarding support for creation of the ecosystem includes research activities on the theme of food and wine, financial, technological and marketing activities carried out by

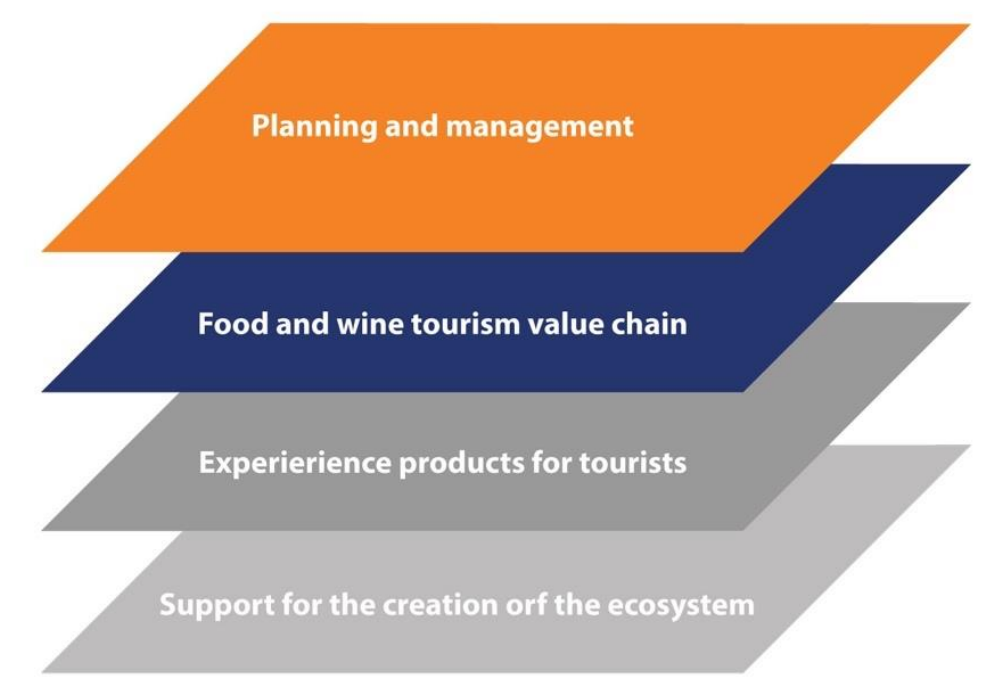
centers, financial institutions, private partners who, with their different missions, can complete the creation and management of the ecosystem.

1. There are many studies that identify culture as one of the main motivations for travel, and amongst these the study Cultural as determinant of the

attractiveness of a tourism region by Ritchie and Zins in which culture is a key resource in attracting visitors to a

destination is very interesting.

\begin{tabular}{|l|r|}
\hline Value chain categories & Total number \\
\hline Accommodation facilities & 1326 \\
\hline Wines with a geographical indication mark & 6 \\
\hline Products with a geographical indication mark & 11 \\
\hline Traditional agri-food products & 114 \\
\hline Food and wine events & 192 \\
\hline Restaurants & 1256 \\
\hline Restaurants awarded stars & 1 \\
\hline Educational farms & 60 \\
\hline Active oil mills & 145 \\
\hline Regional tour operators and travel agencies & 96 \\
\hline Slow Food Presidia & 5 \\
\hline Wineries & 100 \\
\hline Regional wine shop & 1 \\
\hline Basilicata wine tourism movement & 1 \\
\hline Protection consortia & 16 \\
\hline Regional cooking school & 1 \\
\hline Microbreweries & 10 \\
\hline
\end{tabular}

Table 1 Value chain categories 


\begin{tabular}{|l|r|}
\hline Categories offering a food and wine tourism product & $\begin{array}{l}\text { Number of food and wine } \\
\text { tourism offers }\end{array}$ \\
\hline Regional tour operators and travel agencies & 5 \\
\hline Wineries & 12 \\
\hline Basilicata wine tourism movement & 3 \\
\hline Educational farms & 60 \\
\hline
\end{tabular}

Table 2 Categories offering food and wine tourism products
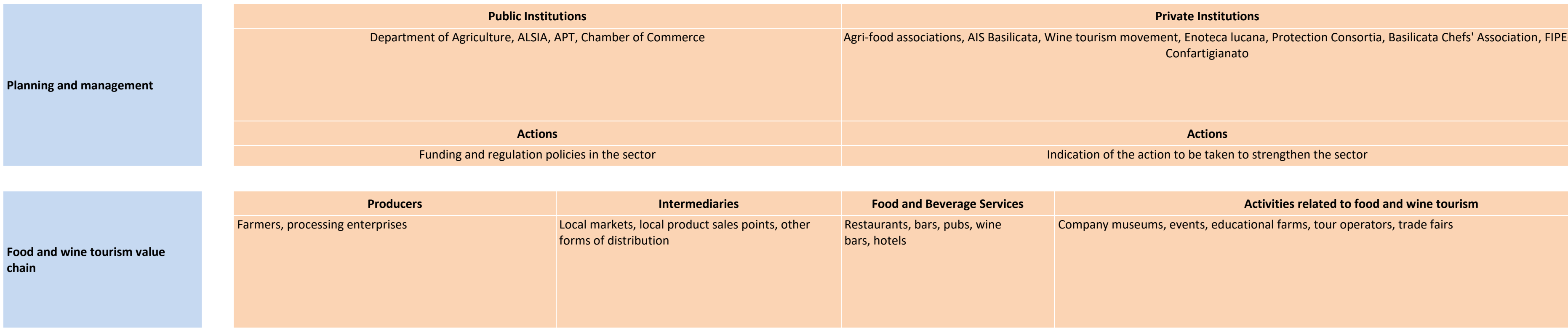

\section{Food and Beverage Services \\ Activities related to food and wine tourism} bars, hotels Company museums, events, educational farms, tour operators, trade fairs

Experiential tourism products originating from the combination of the elements of the food and wine tourism value chain

Tourism product design
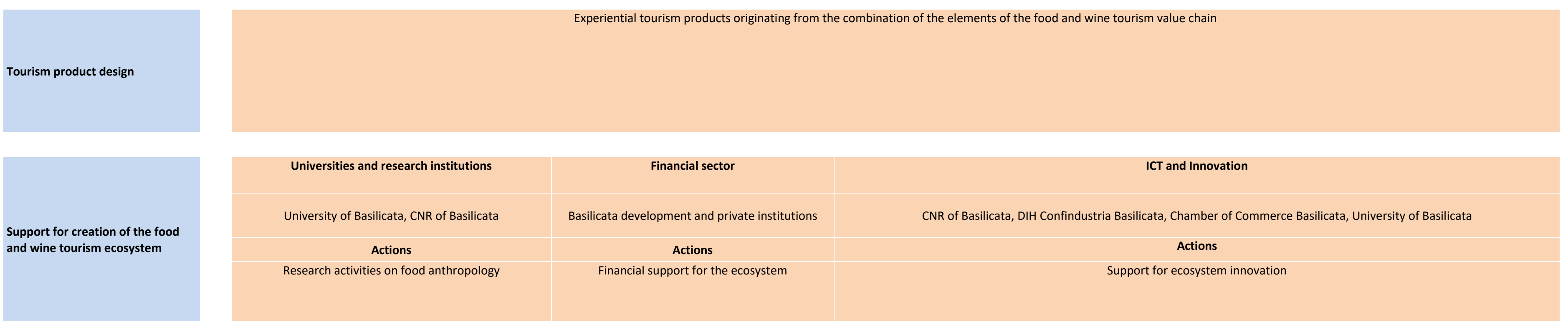

\begin{tabular}{|c|c|}
\hline Universities and research institutions & Financial sector \\
\hline University of Basilicata, CNR of Basilicata & Basilicata development and private institutions \\
\hline Actions & Actions \\
\hline Research activities on food anthropology & Financial support for the ecosystem \\
\hline
\end{tabular}

ICT and Innovation

CNR of Basilicata, DIH Confindustria Basilicata, Chamber of Commerce Basilicata, University of Basilicata Actions

Support for ecosystem innovation 
and wine tourism ecosystem as a model able to determine local development through the involvement of all the players essential to the holistic development of the territory. Four levels of the ecosystem have been identified, namely: Planning and

management, Food and wine tourism value chain, Food and wine tourism product design, Support for creation of the ecosystem, of which the value chain above all, representing the core of the entire ecosystem, was investigated in depth in our study.

themselves in an increasingly crowded

market, and the search for positioning involves creation of new tourism products based on the authenticity, sustainability and originality of the destination, all elements able to satisfy the motivations dictating demand especially in the current situation of the symmetrical shock caused by Covid 19. The travel ban seems to be the right moment to speed up reorganization of a territorial offer able to satisfy the demand for sustainability to which the need for security has been added.

A tourism product able to meet these need is food and wine tourism, a form of tourism typified by a constantly growing demand, with a high spending power and distributed in a balanced way in space and time, all of these factors that represent a solution to problems of overcrowding and seasonality. It is a kind of tourism that succeeds in promoting local development especially in inland areas, and acts effectively in the process of creating the image of the tourist destination.

Starting from the concept of a tourism product and the importance that food and wine tourism could have for a rural region like Basilicata, we have envisaged the food
There are many elements of the value chain: quality agri-food products with a geographical indication label, traditional agricultural products, the wine production chain, the oil production chain,

accommodation services, catering services with Michelin star restaurants, travel agency and tour operator services, educational

farm services, etc.

However, these are elements that to date do not offer forms of synergy and important partnerships, and are isolated elements that are unable to fulfil their potential precisely because they are not interconnected within an ecosystem.

The challenge for destinations is therefore to make use of the obvious advantages of food and wine tourism through technological innovation but above all through a process innovation based on knowledge and organisation of their territory in order to build a tourism offer designed according to the market logic.
The main challenge concerns the need to create and market themed touris experiences in rural areas of Basilicata, areas where most of the traditional local products are concentrated but which each year risk being progressively forgotten due to depopulation and the loss of diversity in agricultural cultures. Food and wine tourism products in particular must be

based on: development of local products characterized by guaranteed traceability, development of sustainable products,

reduction of waste, and cultural tradition. 


\section{Bibliography}

A practical guide to tourism destination management, the World Tourism Organization, 2007

A proposed framework for measuring the effectiveness of social media: a study of Irish

tourism, C. Barcoe, G. Whelan, Sustainable tourism VIII, WIT, 2018.

Can you measure the ROI of your social Media Marketing? D.L. Hoffman, M.Fodor, MIT Sloan mangement review, 2010.

Cinema in Basilicata: impatti su economia e turismo, D. Colangelo, Feem Percorsi, 2018.

Constructing Indicators of culinary tourism strategy: an application of resource-based theory, J.S. Horng, C.T. Tsai, Journal of travel and tourism Marketing, 2012.

Culture as determinant of the attractiveness of a tourism region, J.R.Brent Ritchie,M. Zins, Annals of tourism research, 1978.

Food and tourism experience, OECD studies on tourism, 2012

Food and wine tourism, FactorYmpresa turismo, 2018

Handbook on E-marketing for tourism destination, the World Tourism Organization 2014

Handbook on tourism destination branding, the World Tourism Organization, 2009.

Handbook on tourism product development, the World Tourism Organization, 2011.
Piano strategico per lo sviluppo del Turismo, Ministero per i beni e le attività culturali del turismo 2017-2022.

Rapporto sulle produzioni agroalimentari vitivinicole italiane DOP, IGP, STG, Ismea Qualivita, 2018.

The Competitive Destination, Ritchie J.R.

Brent, Crouch Geoffrey I., Cabipublishing, 2003

Second Global report on Gastronomy tourism, the World Tourism Organization, 2017.

Social Media marketing within Small and Medium sized tourist enterprises, M. Lindqvist, 2017.

The Travel and Tourism Competitiveness Report, World Economic Forum, 2017.

Turismo e Enogastronomia, Isnart Unioncamere, 2018.

Un Modello per la competitività sostenibile delle destinazioni turistiche, A.Magliulo, 2014.

Università degli studi di Bergamo, World food travel association, Rapporto sul turismo enogastronomico italiano, 2018

Web Analytics 2.0, A. Kaushik, Hoepli, 2010 


\section{Appendix}

The following is an in-depth description of the main elements, offered in Basilicata, which form the core level of the entire ecosystem, the food and wine tourism value chain. Research into these elements was performed using various sources: official lists compiled by regional authorities for the identification of certain categories of producers, official lists of the Basilicata region for the

identification of certain types of services: accommodation, travel agencies and tour operators,

educational farms. National sources were helpful in identifying catering services. Finally, digital

sources and data were used to process further information useful for research.

\section{Accommodation}

Accommodation is an essential service for the tourism industry indispensable for creating the tourism product. In Basilicata there are 227 hotel accommodation facilities and 1289 non-hotel facilities for a total of 1516 facilities.

Hotel facilities

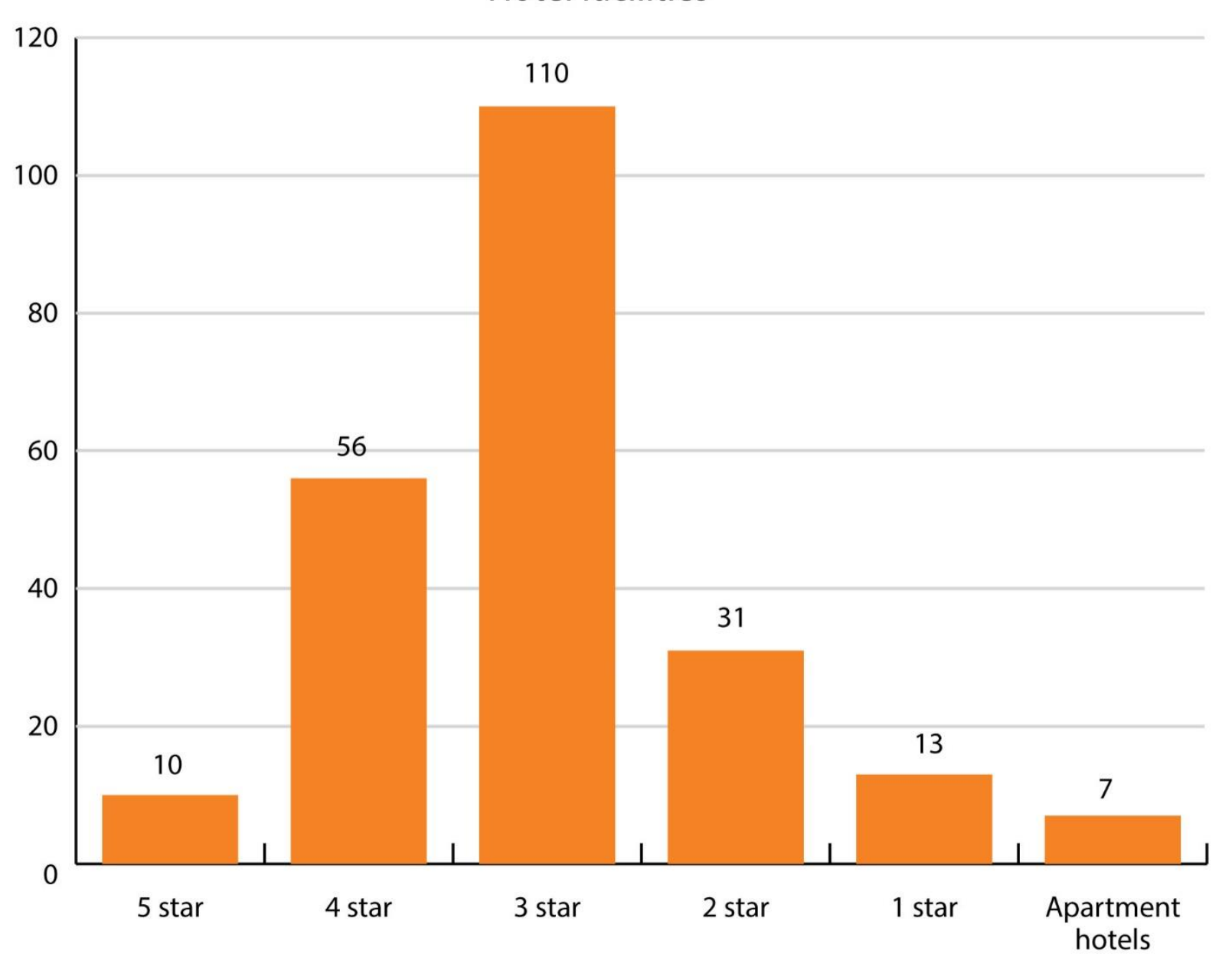

Figure 4: Hotel facilities

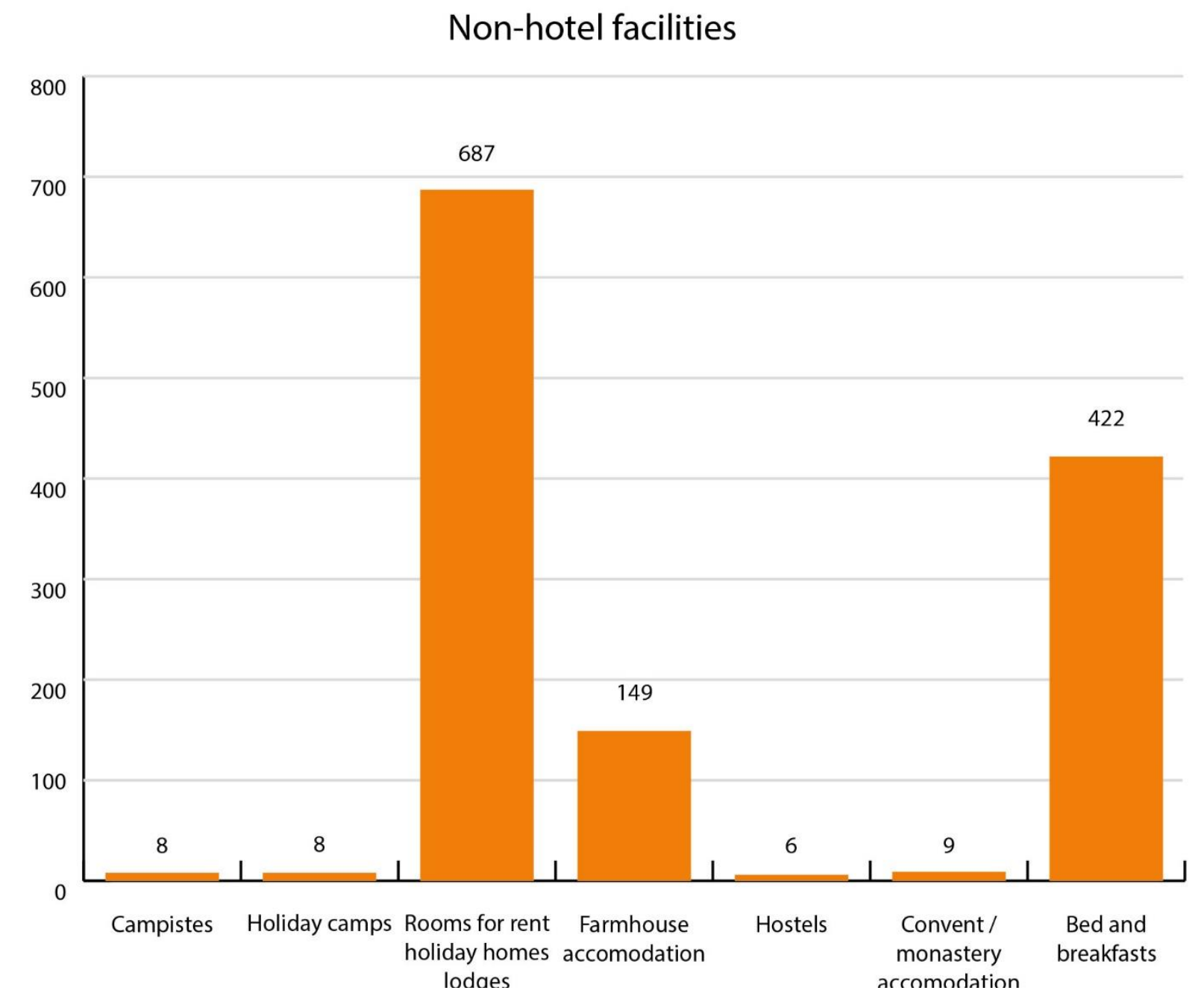

Figure 5: Non-Hotel facilities 


\section{Quality food and wine products}

In Basilicata there are 10 certified gastronomic products: Silano Caciocavallo cheese (PDO), Moliterno Canestrato cheese (PGI), Rotonda white beans (PDO), Sarconi beans (PGI), Rotonda red aubergines (PDO), Filiano Pecorino cheese (PDO), Senise peppers (PGI), Vulture oil (PDO), Matera bread (PGI), Altamura lentils (PGI), Picerno Lucanica sausage (PGI).

There are 6 quality wines, Aglianico del Vulture Superiore (PDO), Aglianico del Vulture (PDO), Matera (PDO), Grottino di Roccanova (PDO), Terre dell'Alta val d'Agri (PDO), Basilicata (PGI).

There are two TSG products: Mozzarella and Neapolitan pizza.

At a national level, MIPAAF, the Ministry of Agricultural, Food and Forestry Policies, promotes traditional products (Traditional Agri-Food Products - PAT), i.e. agricultural or livestock products that are produced according to ancient recipes. The requirement for recognition as a PAT is that they must be "obtained by processing, conservation and maturing methods consolidated over time, homogeneous throughout the territory concerned, according to traditional rules, for a period of no less than twentyfive years". The official list, now at the 20th update includes 149 specialities in Basilicata.

\section{Food and wine events}

Events are considered authentic tourist attractions and are some of the most dynamic resources for the tourism industry with temporary and unique characteristics.

In 2018 a regional calendar of events for promotion of food and agriculture in Basilicata called \#GustoBasilicata was published, and included food and wine events taking place in Basilicata. Ther are 192 events in 115 municipatities grouped into eight categories: fruit and vegetables, livestock, cereals, wine, traditional local products, extra virgin olive oil, fish and chestnuts.

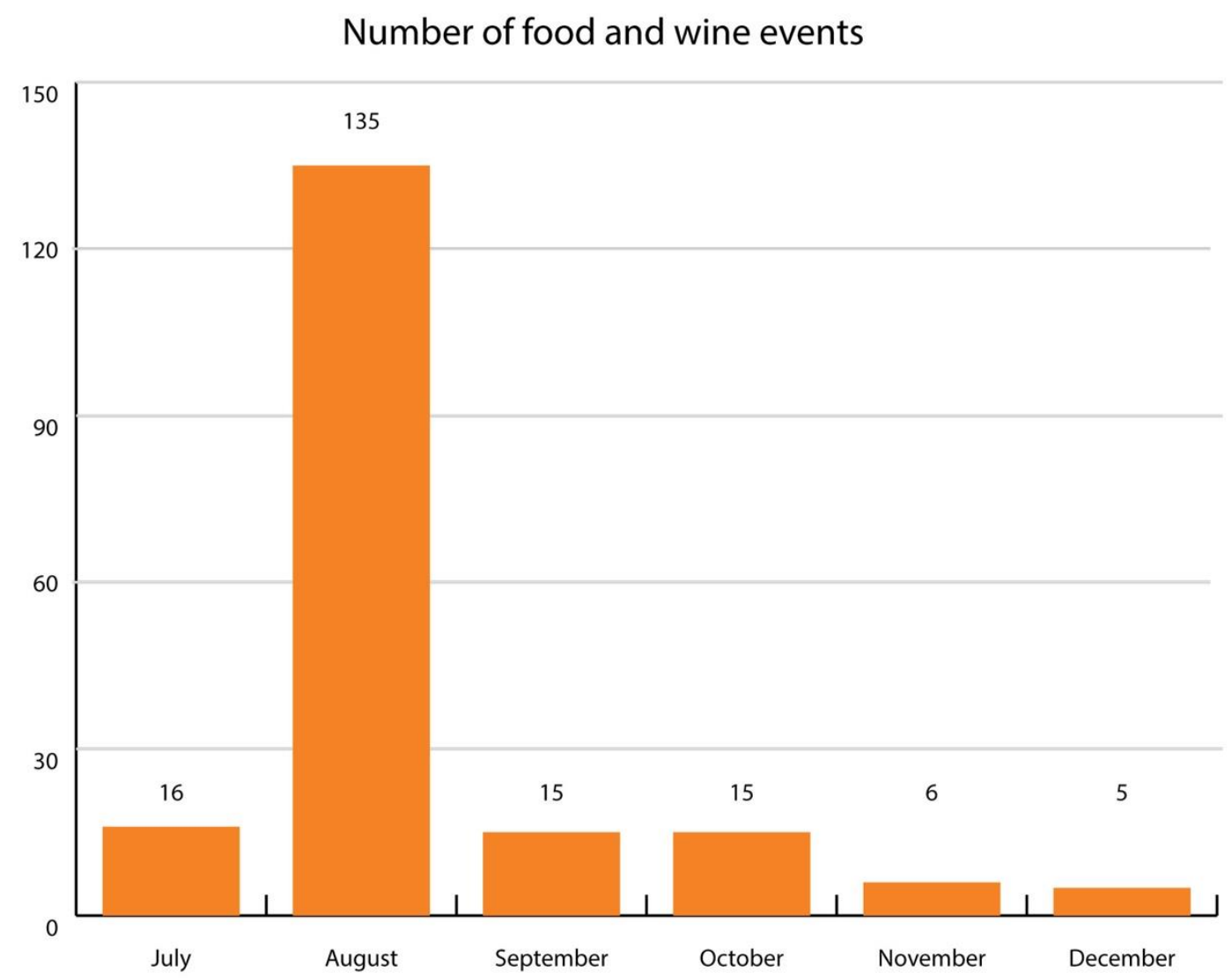

Figure 4: The \#Gustobasilicata events

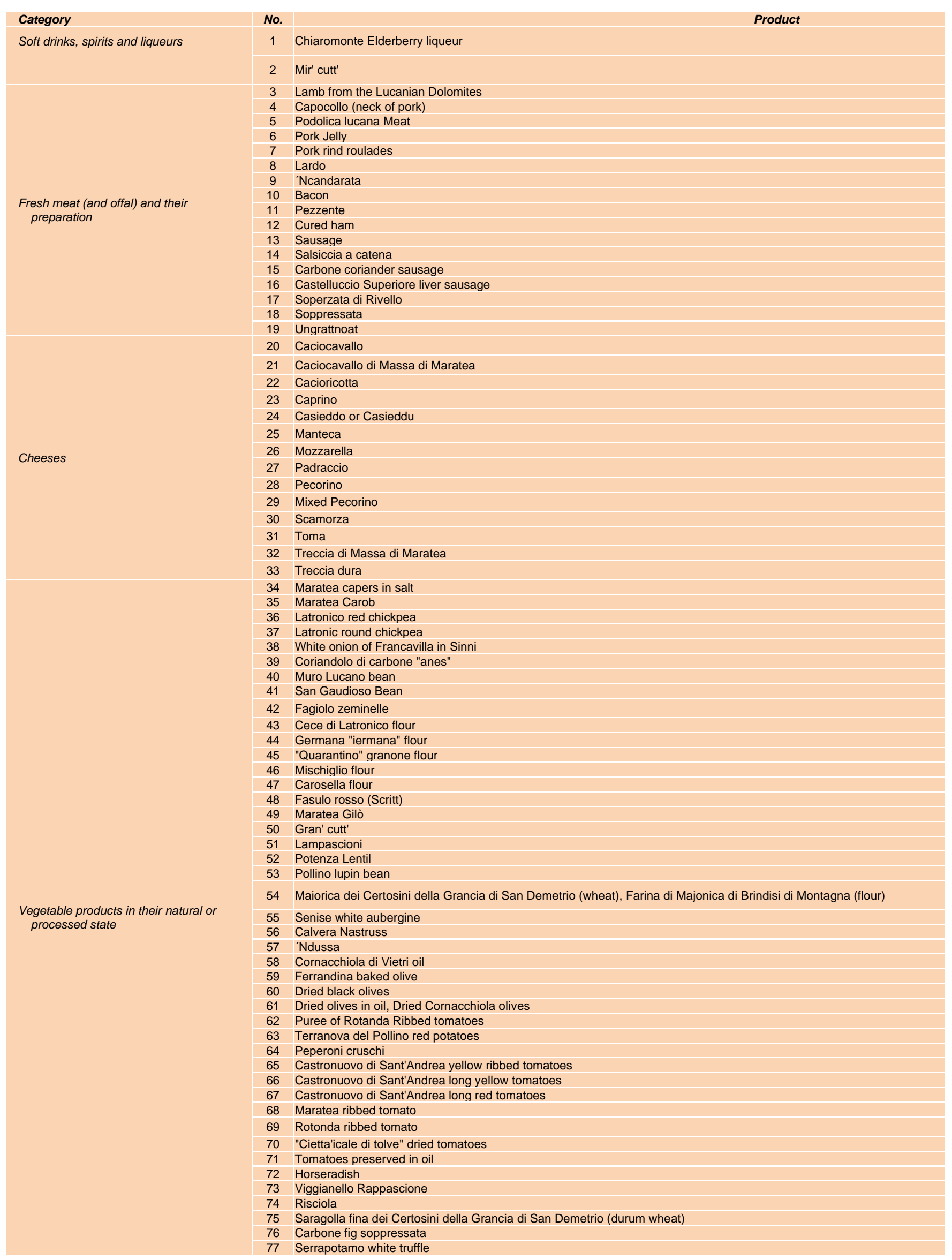




\begin{tabular}{|c|c|c|}
\hline $\begin{array}{l}\text { Fresh pastries and bakery, biscuit and } \\
\text { confectionery products }\end{array}$ & $\begin{array}{l}78 \\
79 \\
80 \\
81 \\
82 \\
83 \\
84 \\
85 \\
86 \\
87 \\
88 \\
89 \\
90 \\
91 \\
92 \\
93 \\
94 \\
95 \\
96 \\
97 \\
98 \\
99 \\
100 \\
101 \\
102 \\
103 \\
105 \\
106 \\
107 \\
108 \\
110 \\
111 \\
112 \\
113 \\
114 \\
115 \\
116 \\
117 \\
118 \\
119 \\
120 \\
121 \\
122 \\
123 \\
125 \\
126 \\
127 \\
128\end{array}$ & 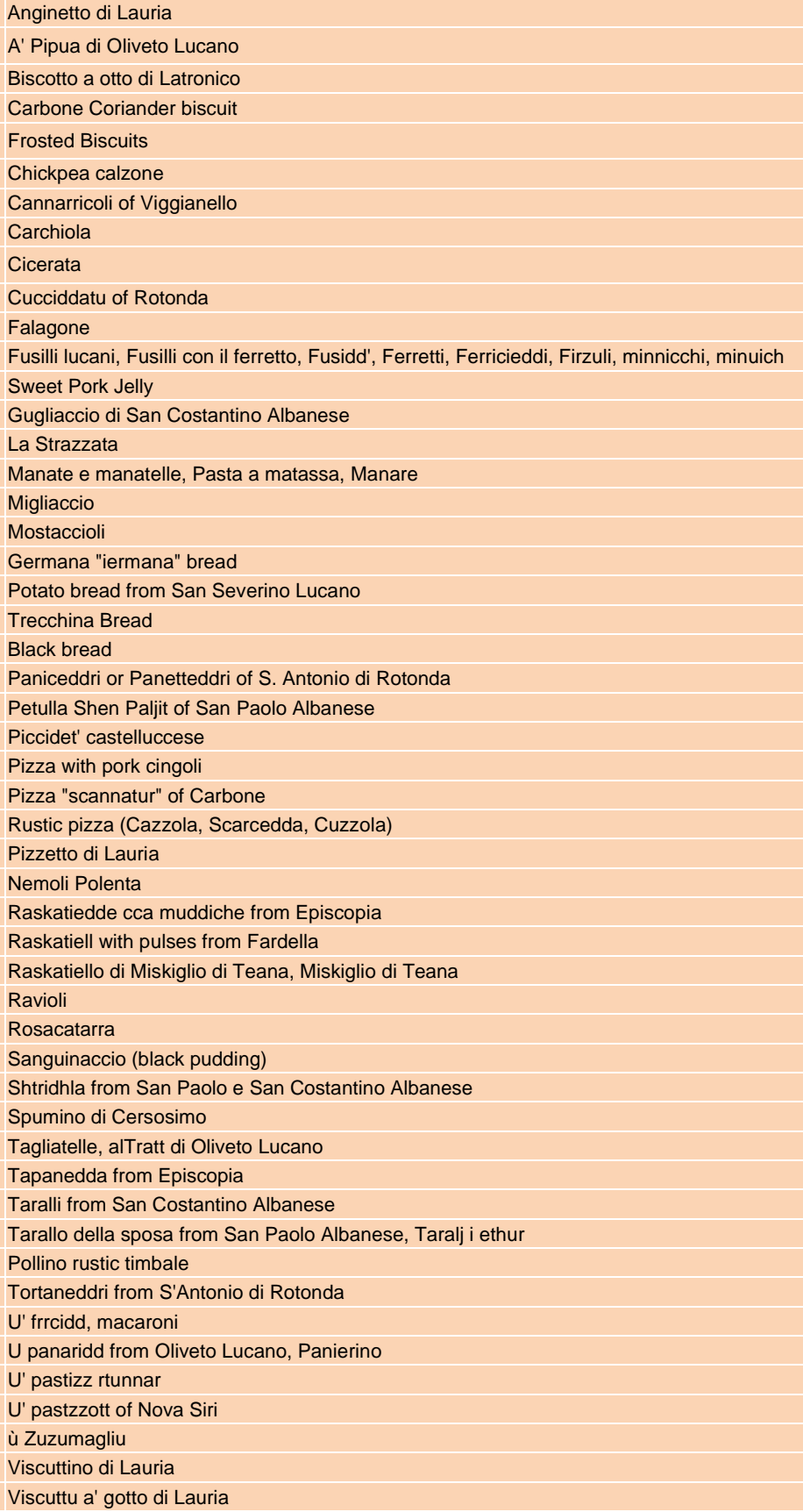 \\
\hline Gastronomy products & $\begin{array}{l}129 \\
130 \\
131 \\
132 \\
133 \\
134 \\
135 \\
136 \\
137 \\
138 \\
139 \\
140 \\
141 \\
142\end{array}$ & 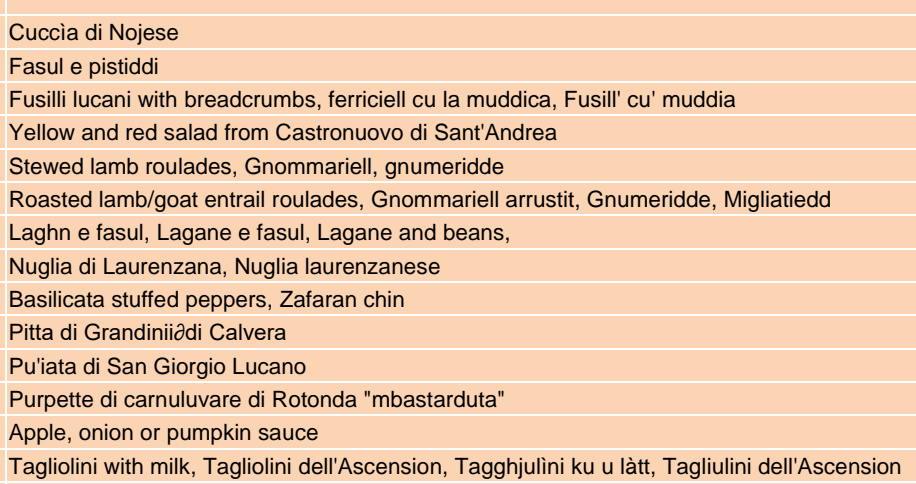 \\
\hline $\begin{array}{l}\text { Preparations of fish, mollusscs and } \\
\text { crustaceans and spocial farming } \\
\text { techniques for them }\end{array}$ & $\begin{array}{l}143 \\
144 \\
145 \\
146\end{array}$ & $\begin{array}{l}\text { Maratea salted anchovies } \\
\text { Maratea sasted alicicoculi } \\
\text { Maratea Garum (Fish Sauce) } \\
\text { Basilicata honey (r'miel) }\end{array}$ \\
\hline $\begin{array}{l}\text { Products of animal origin (honey, various } \\
\text { dairy products except butter) }\end{array}$ & & $\begin{array}{l}\text { Basilicata honey (r'miel) } \\
\text { Ricotta } \\
\text { Ricotta forte } \\
\text { Salted Ricotta }\end{array}$ \\
\hline
\end{tabular}

Table 3 Basilicata's traditional food products

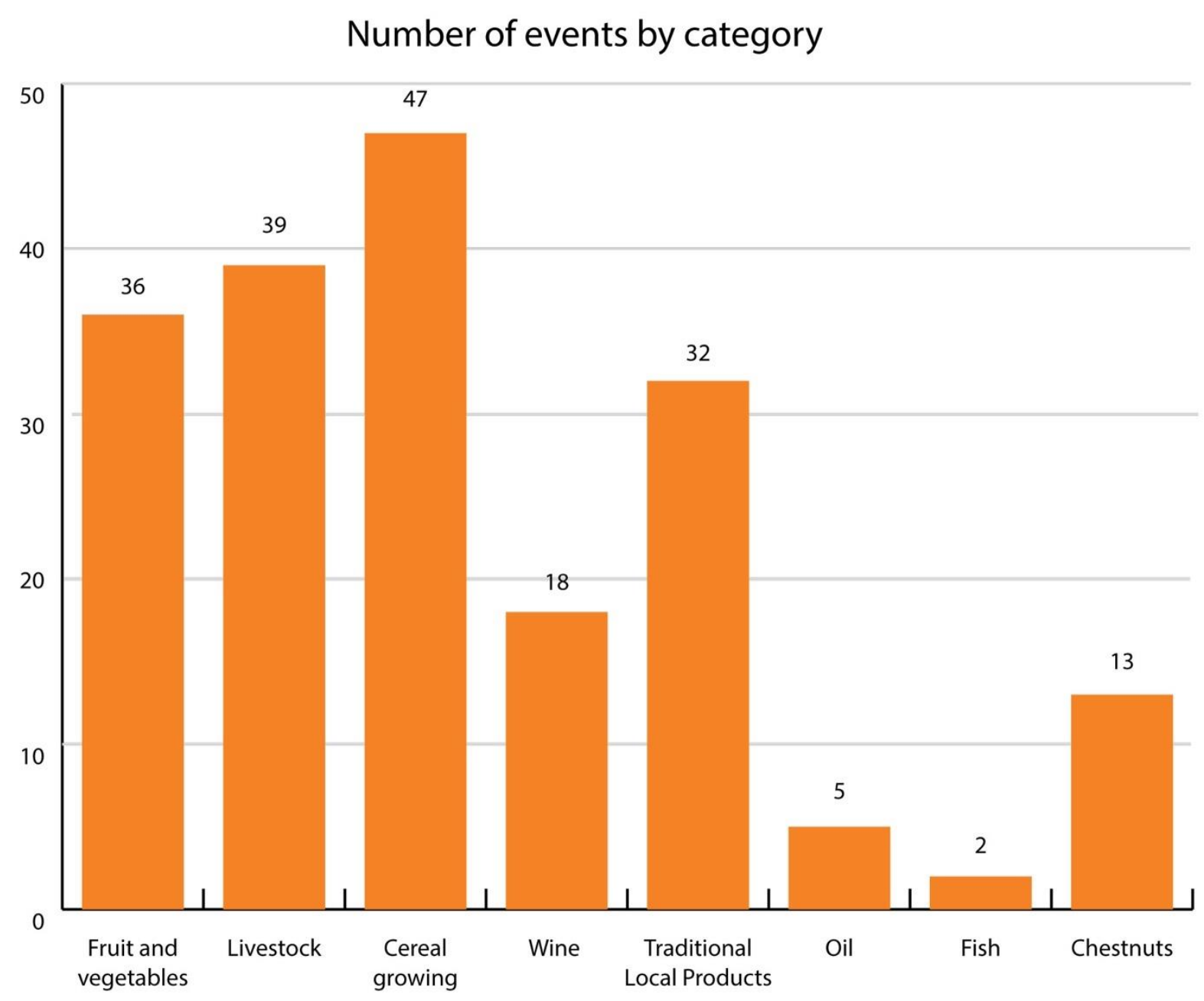

Figure 4: The \#Gustobasilicata events divided by category

\section{Catering services}

In Basilicata there are 1299 businesses registered under the ATECO business classification code 56.1 .e. catering activities, 203 of which are present in Lucanian hotel facilities, and $62.6 \%$ of which are individual companies. It is estimated that they spend a total of 7,070,717 Euro to purchase raw materials for the preparation of meals.

The digital guide, The Fork, lists 81 restaurants in the 131 municipalities of Basilicata, 63 of which 63 offer gastronomic specialities indicated as traditional/from Basilicata. It is possible to sample the Basilicata cuisine at an average price of $22.09 €$ ( 22.13 in the province of Potenza and 21.89 in the province of Matera). During the analysis period we counted 2056 ratings for 45 restaurants which received an average rating of 8.5 out of 10 . There is one Michelin star restaurant in Basilicata and it is located in Matera.

\section{Educational farms}

The educational farms of Basilicata are farms and farm holiday businesses that welcome families, groups, especially schoolchildren, to teach the values of rural life through educational workshops,

There are 60 educational farms in Basilicata with varied and original learning paths, many of which are 
linked to food and wine traditions.

In addition to offering an interesting range of food and wine, the educational farms are also quite uniformly distributed in the territory, covering all areas of Basilicata, and present in municipalities such as: Melfi, Rionero, Venosa, Acerenza, Cancellara, Bernalda, Castelmezzano, Chiaromonte Marsico Nuovo, Marsico Vetere, Matera, Noepoli, Nova Siri, Rotondella, San Severino Lucano, Noepoli and Terranova del Pollino.

\section{Olive Oil producers}

Olive oil is another traditional rural that has left its mark on the landscape of Basilicata since ancient times.

There are three production areas: Vulture, Lower Val d'Agri, Lower Matera Hills. The most important olive growing centres in Vulture are Melfi, Rionero in Vulture, Barile, Rapolla, Acerenza, Lavello an Venosa. The most widespread olive tree quality in the area is the Ogliarola, which bears fruit on volcanic soil. In the lower Materana hills the best quality production areas are Ferrandina, Grassano, Grottole, Salandra, Montescaglioso and Bernalda. In this territory the most widespread variety is the Maiatica di Ferrandina, from which an excellent oil is obtained, but also excellent table olives, in fact one of the gastronomic specialities of Ferrandina are oven-dried olives. The other main olive growing area is the lower Val d'Agri in the municipalities of Aliano, S. Arcangelo, Roccanova and Missanello.

In Basilicata there are five million olive trees, 30 thousand olive growing companies, and 145 active mills, and olive oil from the Vulture area has been awarded PDO certification.

\section{Slow Food presidia in Basilicata}

Slow Food Presidia support small-scale traditional products that risk disappearing, enhance the value of the land, revive ancient crafts and processing techniques and save native animal breeds and varieties of fruit and vegetables fruit from extinction. In particular, the presidia focus on the concept of environmental sustainability, i.e. respect for the fertility of the soil, for hydrographic ecosystems, maintenance of traditional cultivation and land management practices and the concept of soctar sustainabitity. There are 5 slow Food Presidia in Basiticata. Caciocavallo podolico di Basiticata, Fagiolo rosso scritto del Pantano di Pignola, Oliva infornata di Ferrandina, Pera Signora della valle del Sinni, Pezzente della montagna materana.

\section{Wine}

The wine sector is a segment of the food and wine tourism value chain that is fundamental for the positioning of a territory for food and wine purposes. In Basilicata, it is a sector that accounts for $2.6 \%$ of regional agricultural production, with 5,196 hectares of vineyards, 1,300 of which are used for regional controlled designation of origin (DOC) wines. There are four thousand wineries, one hundred of which market their own products with a total of 400 labels and 6.7 million bottles of wine.

\section{Microbreweries}

The local production of beer is increasingly attracting the interest of tourists and so these microbreweries are establishing themselves as increasingly important food and wine resources for territory. This is due to the success of local quality products on the market alongside the artisan products. More and more tourists want to visit the breweries and take part in dedicated events. There are 10 microbreweries in Basilicata.

\section{Travel agencies and tour operators}

According to the official hist of travel and tourism agencies of Basiticata, there are 96 companies operating in Basilicata, 84 have an AB licence, 5 have an A licence and 7 have a B licence.

June 2020

FEEM - Fondazione Eni Enrico Mattei www.feem.it

The work must be cited as: Bencivenga, A., Percoco A. (2020): Basilicata's food and wine tourism ecosystem,

Recreating the offer to recover \#TravelTomorrow, Fondazione Eni Enrico Mattei, Milano.

Angelo Bencivenga is senior researcher on the issues of sustainable tourism and sustainable local development.

Layout by: Texal di Matteo Bernecoli. 


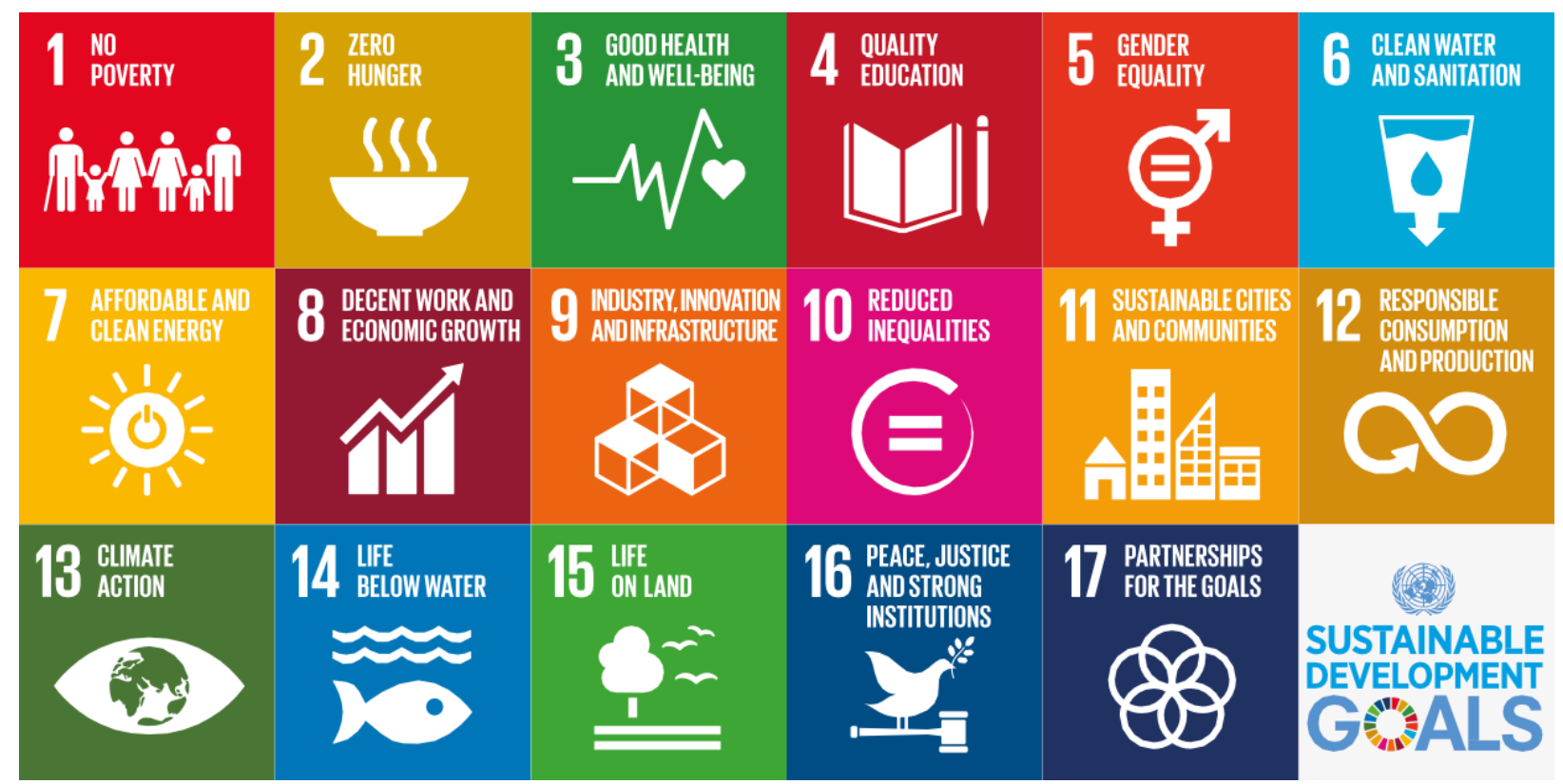

The Fondazione Eni Enrico Mattei (FEEM) founded in 1989, is a non profit, policyoriented, international research center and a think-tank producing high-quality, innovative, interdisciplinary and scientifically sound research on sustainable development. It contributes to the quality of decision-making in public and private spheres through analytical studies, policy advice, scientific dissemination and high-level education. Thanks to its international network, FEEM integrates its research and dissemination activities with those of the best academic institutions and think tanks around the world.

\section{Fondazione Eni Enrico Mattei}

Corso Magenta 63, Milano - Italia

Tel. +3902.520 .36934$

Fax. +39.02 .520 .36946$

E-mail: letter@feem.it www.feem.it 